\title{
Ermutigende Ergebnisse
}

\section{Keine Gefahr für Neugeborene SARS-CoV-2-positiver Mütter}

\author{
Es scheint nicht nötig zu sein, SARS-CoV-2-infizierte Mütter auf der \\ Entbindungsstation von ihren Neugeborenen zu trennen. Keines der \\ Kinder entwickelte in einer New Yorker Studie klinische Hinweise auf \\ eine Virusübertragung, selbst wenn es gestillt wurde.
}

B islang ist nur wenig über eine mögliche vertikale oder perinatale Übertragung von SARS-CoV-2 bekannt. Entsprechend groß sind die Ängste und Sorgen der Schwangeren. In einer retrospektiven Kohortenstudie haben Dani Dumitriu vom Columbia University Irving Medical Center, New York, und Kollegen jetzt die medizinischen Daten von 101 Neugeborenen und ihren 100 Müttern analysiert. Bei 99 Frauen war zwischen dem 13. März und 24. April 2020 per PCR eine SARS-CoV-2-Infektion nachgewiesen worden.

\section{Rooming-in mit besonderen} Hygieneregeln - kein Problem $81 \%$ der Kinder wurden nach der Geburt auf der Entbindungsstation im Zimmer der Mutter im eigenen Bettchen in $180 \mathrm{~cm}$ Entfernung zur Mutter (Rooming-in) versorgt. Die Frauen trugen einen Mund-Nasen-Schutz und wurden unter Einhaltung fester Hygieneregeln zum Stillen der Kinder ermuntert. Tatsächlich wurden $90 \%$ der Kinder zumindest teilweise gestillt. Abgesehen von einigen weiteren Präventionsmaßnahmen wie Einzelzimmer, enger Gesundheitsüberwachung des Personals sowie der Beschränkung von Besuchen wurde nach den üblichen Abläufen der Geburtsstation verfahren. Hautkontakt zwischen Mutter und Kind war erlaubt. $19 \%$ der Kinder wurden auf der Neugeborenen-Intensivstation versorgt. Sie durften erst nach einer 14-tägigen Isolationszeit von ihren Müttern besucht werden.
Bis zum 25. Lebenstag wurden bei den Neugeborenen insgesamt 141 SARSCoV-2-Tests durchgeführt. 70 Kinder wurden nur einmal getestet. Bei klinischen Auffälligkeiten wie Fieber oder respiratorischen Symptomen erfolgten weitere Tests. 135 Tests fielen negativ aus, bei zwei Neugeborenen waren die Testergebnisse unklar und wurden als geringe Viruslast gewertet. Eines dieser Kinder wurde am Tag 0 fraglich positiv getestet, nachdem seine Mutter während der Geburt Fieber entwickelt hatte. Eine Kontrolle am zweiten Lebenstag erbrachte bei diesem Säugling ein negatives Testergebnis. Das zweite Kind wurde an Tag 3 positiv getestet, nachdem sich bei der Mutter Symptome eingestellt hatten. Dieses Kind wurde kein zweites Mal getestet, zeigte im weiteren Verlauf aber keine klinischen Auffälligkeiten.

\section{Höheres Risiko eines \\ Neugeborenenikterus}

$90 \%$ der Kinder wurden von asymptomatischen Frauen oder Frauen mit leichten Symptomen geboren, die Mütter der restlichen $10 \%$ waren schwer oder sogar lebensgefährlich an COVID-19 erkrankt. Der Vergleich dieser beiden Gruppen ergab, dass Kinder von Frauen mit schwerer oder lebensgefährlicher COVID19-Erkrankung etwa eine Woche vor dem eigentlichen Termin geboren wurden und häufiger eine Fototherapie wegen eines Neugeborenenikterus benötigten als Kinder von Müttern mit asymptomatischen oder leichten COVID19 -Verläufen ( $30 \%$ vs. $7 \%$ ).
Diese Kohortenstudie lässt also keine Evidenz für eine vertikale Virusübertragung erkennen, obwohl viele Kinder im selben Zimmer wie die infizierten Frauen untergebracht waren und gestillt wurden. Es wird vermutet, dass der Säugling über die Muttermilch einen gewissen Schutz vor der SARS-CoV-2-Infektion erhält, zumal in der Milch spezifische IgA-Antikörper nachgewiesen wurden.

Selbst schwer erkrankte Frauen übertrugen das Virus bei vaginaler Entbindung nicht auf ihr Kind. Deshalb, so Dumitriu und Kollegen, erscheine die Trennung von SARS-CoV-2-positiven Müttern von ihren Neugeborenen und der Verzicht auf das Stillen auf der Entbindungsstation zur Prävention einer SARS-CoV-2-Infektion nicht gerechtfertigt.

Dr. Christine Starostzik

Basierend auf: Dumitriu D et al. Outcomes of neonates born to mothers with Severe Acute Respiratory Syndrome Coronavirus 2 infection at a large medical center in NewYork City. JAMA Pediatr 2020;e204298

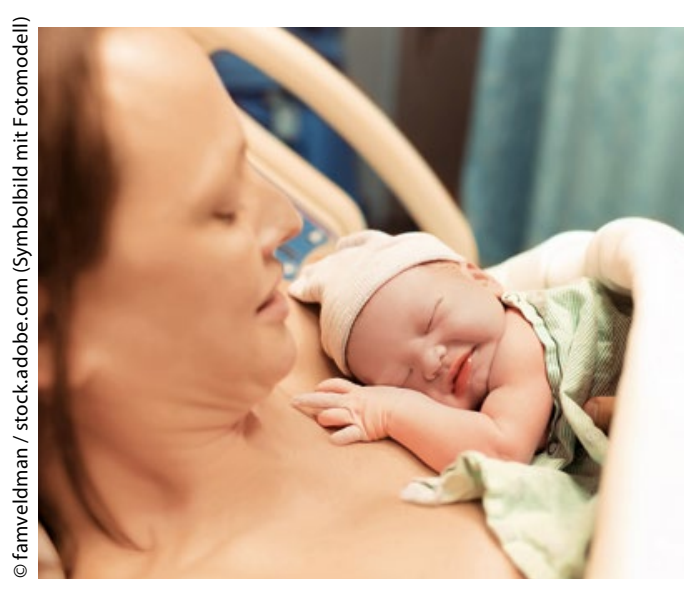

Selbst wenn eine Mutter schwer an COVID-19 erkrankt ist, scheint sie die Viren bei einer vaginalen Entbindung nicht auf das Kind zu übertragen. 